\title{
Effects of Biochar Amendment on Soil Problems and Improving Rice Production under Salinity Conditions
}

\author{
Gulaqa Anwari ${ }^{1.2^{*}}$, Ajmal Mandozai ${ }^{3}$, Jin Feng ${ }^{1 \#}$ \\ ${ }^{1}$ College of Agronomy, Jilin Agricultural University, Changchun 130118, Jilin, China. \\ ${ }^{2}$ Agronomy Department, Agriculture Faculty, Kunduz University, Kunduz Province 3501, Afghanistan. \\ ${ }^{3}$ Plant Biotechnology Center, College of Agronomy, Jilin Agricultural University, \\ Changchun 130118 Jilin, China.
}

\section{Corresponding Author email: \\ * gulaqa.anwari@gmail.com \\ \# jinfeng911@126.com}

\section{Article History}

Received: 09 September 2019

Revised: 04 October 2019

Accepted: 21 October 2019

Published: 28 October 2019

\section{Student(s)}

- Gulaqa Anwari

- Ajmal Mandozai

Academic Year: 2018-19

Course Level: Master

Course Name: Training and Scientific Writing

Course year: IInd $-1 I^{\text {rd }}$ Semester

$\operatorname{Mentar}(\mathrm{s})$

- Jin Feng

\begin{abstract}
Soil with poor physio-chemical and biological properties prevent plant growth. These poor characteristics may be due to soil creation processes, but also include largely inappropriate agricultural practices and/or anthropogenic pollution. During the last 4 decades, the world has lost onethird of its cropland due to pollution and erosion. Therefore, a series of operations is required to improve and recover the soil. Biochar is a new multifunctional carbon material extensively used as a modifier to improve soil quality and crop production. Previous studies have discussed the properties of biochar with varying soil pollutants and their effects on soil productivity and carbon sequestration. Comparatively, little attention has been paid to the effects of biochar application on rice growth in the problem of soils, especially in the saline-sodic soils. A comprehensive review of the literature with a high focusing on the effects of biochar application on problem soils and rice-growing under salinity conditions is needed. The present review gives an overview of the soil's problem, biochar amendment effects on physicochemical properties of soil, and how the biochar amendment could interact in soil microbes and root with remediation under salinity conditions for improving rice productivity. The findings of this review showed that biochar application can improve soil quality, reduce soil's problem and increase rice production under salinity conditions. It is anticipated that further researches on the biochar amendment will increase our understanding of the interactions of biochar with soil components, accelerate our attempts on soil remediation, and improve rice production under salinity conditions.
\end{abstract}

Keywords: soil's problem, biochar application, rice productivity, salt-affected soil, salinity conditions. 


\section{Introduction}

Soil is a valuable natural ecosystem, composite of the mineral, organic matter, gases, liquids, and organisms with dynamic interactions. Healthy soil is a basis of crop productivity; it can produce wholesome crops that in turn provide food safety and healthy livestock which improve human welfare. Soil health is a state of soil that meets a range of ecosystem functions involving (i) keeping plant and animal productivity and biodiversity, (ii) supporting or enhancing water and air quality, and (iii) maintaining human health and dwelling [1]. Plants grown in the soil mostly are dependent on soil health. If the soils are in poor conditions, such as salinization, compaction, acidification, and inaccurate-modification, they become improper for crop production, moreover, anthropogenic activities have not only changed and deteriorated soil properties but also introduced pollutants, such as synthetic organic compounds and heavy metals into soils [2]. Both contaminated and poor soils that are the main obstacles to prevent plant growth are known as soil's problems. Saline-sodic soil problem is the main stress for crop production. Whereas various management strategies have been proposed and developed to improve the problem of salt-affected soils among which biochar amendment has an excellent promise [3] [4]. Therefore, salt-affected soils in the arid and semiarid regions of the world have limited crop production, as the northeast of China's in Songnen Plain is one of the three largest saline-alkaline and saline-sodic soils in the world's distributed areas that have been affected by salinity and sodicity (about 3.73 million hectares of land) [5]. High soluble salts and sodium limit the growth of plants due to osmotic stress and toxicity; and more exchangeable $\mathrm{Na}^{+}$breakdown soil materials, reduce aeration and hydraulic conductivity; two variables that have an impact on soil evaporation and moisture [6]. Salts in high osmotic activities through their pressures affect plant growth by restricting the uptake of water by the roots, while salinity can also affect plant growth because of the high concentration of salts in the soil solution interfered and caused imbalance to absorption of essential nutritional ions by plants [7].

The amelioration of salt-affected soils has focused on the activities of; includes salt leaching and the use of various types of recovering as a modifier (biochar and organic matter). Biochar is a kind of biomass that is produced by burning in the absence or the presence of small amounts of oxygen at a temperature of 300 to $1000{ }^{\circ} \mathrm{C}[8]$. Biochar has different types that all types do not have the same effect on a specific soil, and so any biochar cannot be equally distributed in all soil types [9]. Biochar besides the significant effect on improving soil's physical and chemical properties also increase the movement of water directly into the soil and prevent waterlogging of saline-sodic soils. However, this decreases the water retention time in the soil, which is likely due to Electrical Conductivity (EC) change in the leaching from biochar treatments [10].

Generally, many biochar additions in saline-sodic soil studies are shown that biochar significantly reduced EC of saturated paste extracts (ECe), exchangeable sodium percentage (ESP), sodium adsorption ratio (SAR), and some of the soluble and exchangeable cations [9]. However, the nutrient concentrations in the plant tissues and nutrient availability was highest when the salt-affected soil received a combined application of biochar, and crop in the treatment with biochar application in the saline-sodic soils, had the highest survival rate, nutrient contents, dry matter, and yield [11]. The significant plant response to the biochars application, particularly in the saline-sodic soil, was qualified to play an important role in improving soil physical/chemical properties, and in facilitating salt leaching from the roots zone [7]. As well, the use of biochars can ameliorate general soil quality, such as soil $\mathrm{pH}$, water holding capacity, infiltration, and fertilization use efficiency by plant and improve crop productivity [6]. Therefore, biochar should be useful for saline-sodic soil reclamation and reducing the negative effect on water quality of excess nutrient input [11]. Salt-affected soils induce detrimental influences on paddy growth and yield. Some detrimental effects of saline-sodic soils on growth could include osmotic effects reducing water uptake by rice plants, toxic effects of ions such as $\mathrm{Na}^{+}, \mathrm{Cl}^{-}$, and nutritional imbalances, but the influences of salinity on rice growth could be decreased by reclaiming soil with the application of organic matter such as amendment of biochar [12]. 
Most of the earlier reviews focused on the interactions between biochar and soil components and/or contaminants with limited attention to plant growth, likewise, the investigating studies on rice growth with the biochar amendment in the soil salinity problems (saline-sodic and saline-alkaline soils) have been mainly overlooked. The general objectives of this review are considered to summarize the current knowledge on the key role of biochar in improving soil properties and plant growth, as well as outlining perspectives, challenges, and future pathways for biochar production and its remediation effects in salt-affected soils. The particular objectives are to (i) provide an overview of the important parts of soil properties soils problem and their effects on plant productivity especially rice growth under salinity conditions, (ii) conceder on the properties and functionality of biochar, (iii) discuss the main role of biochar on soil pollution, and (iv) present a conclusion related to the potential application of biochar for improving soil health and rice growth under salinity conditions.

\section{General problems of soils and plant growth}

Plant growth process in soils is very complex. Roots have been playing significant roles in the booster and mechanical backing of plants, absorption of nutrients and water, biosynthesis and storage of chemical compounds, and interactions with biotic and abiotic factors in the soil environment [1]. Wholesome soils authorize to roots to penetrate soil particles, and absorb water and nutrients, and consume oxygen, thus enabling plants to grow up to their maximum potential. While those soils have problems (salinity or acidity), depend on constraints, inhibit roots growth, impede water and nutrient uptake, and reduce plant growth. This part summarizes the general properties of naturally poor or anthropogenic contaminated soils and their effects on plant growth [7]. However, rice as a most sensitive cereal crop to salinity, it is recommended to be grown in salt-affected soils because salinity is often accompanied by waterlogged conditions [13]. Water plays an important role in irrigated rice tends to dissolve the salt molecules, and move out them as runoff or leach them down of paddy fields, and hence reducing salt levels in the rice field [14]. Salts accumulate in soil because of moving saltwater from nearby areas through flooding or low-quality water system, and its $\left(\mathrm{Na}_{1}-\mathrm{Cl}_{2}\right)$ suppress seed germination, causes changes in the physiological characteristics and harm the root arrangement of the rice. The $\mathrm{Cl}_{2}$ activated damage is recognizable by the broadleaf cutting edge indicating burningly while the accumulation of $\mathrm{Na}$ salts causes leaf mottling and rolling. As regards the existing of salinity conditions in the soil reduces the plant's capacity to receive water which decreases growth and development and referred to as a water-shortage impact on saltiness [15].

\subsection{Plant growth in naturally problem soils}

Soil salinity (high levels of water-soluble salt) and sodicity (high levels of exchangeable sodium), called collectively salt-affected soils, naturally soil formations process is slow and long, as it is determined by climate and organisms (plants, animals, and microbes) acting on the local geological surface materials over time and may also be influenced by human activities [16]. Thus, $95 \%$ of the parent material and soils of the world moved to or from their present location, and even $5 \%$ of them are remaining soils of parent materials that contribute as significantly to the physical and chemical properties of the various soils [15]. Salt affected soils (saline and sodic) are exposed to hydrologically modified processes that can affect the chemistry process of soil, carbon cycle and nutrients as well as organic matter decomposition. Salinity and sodicity harm plant health and soil organic carbon stock (SOC), in salt-affected areas. Saline and sodic soils are exposed to several opposing processes that could affect soil microbial biomass and microbial activity [17]. The extent degradability of soil organic matter related to the level of salinity conditions, but limit access to substrates due to the clotting of aggregates resulting in high concentrations of soluble salts. Saline and sodic soils generally contain carbonates, which complicate the dynamics of carbon (C). However, rice is a suitable crop for reclamation of saline-sodic soils problem that has salinity values less than $20 \mathrm{dS} / \mathrm{m}$ [14]. 


\subsubsection{Effects of physical constraints on plant growth}

The influence of physical limitation on soil physical properties includes soil texture, structure, pores, bulk density, organic matter, soil depth, and temperature. The above physical structures depend on soil formation history and can be pointedly influenced by natural forces and human activities [1]. Here is a key role of physical restriction which affects plant growth in compaction soil. In agricultural production, compression typically occurs in the soil to a depth of about $30 \mathrm{~cm}$, and it is estimated that about 68 million hectares of global agricultural lands are the only exposed to the compaction stress by vehicular traffic. If the bulk density exceeds $1.3 \mathrm{~g} / \mathrm{cm}^{3}$ with poor physical and aeration of the roots growth restriction, the roots cannot enter into the soil pores smaller or (micropores) than the diameter of the root cap, therefore the root growth is prevented [18]. The decrease in pore space volume will reduce permeability and the diffusivity of gases and may result in the formation of anaerobic conditions and the high anaerobic conditions will be favorable for the soil desorption of denitrification processes, thereby enhancing soil $\mathrm{N}_{2} \mathrm{O}$ emissions as well as suppressing the activities of beneficial microbes in the rhizosphere. As a result, plant growth is significantly reduced [17]. According to plant growth physiology, the reduction of plant growth functionality due to the high compaction resultant is attributed to the abscisic acid (ABA) accumulation in plants, which first impedes on root-growth and then decreases stomatal conductance and photosynthesis after being translocated to shoots via the transpiration stream. Researchers believe that not just ABA, but another plant growth regulator, ethylene also participates in the plant growth reduction [1].

\subsubsection{Effects of chemical constraints on plant growth}

Soil chemical properties include salinity, acidity, alkalinity, nutrient deficiencies, and sodicity are known as chemical constraints that mainly impact on plant growth. Generally, in acidic soil ( $\mathrm{pH}<5.5$ ), aluminum (Al) and manganese $(\mathrm{Mn})$ become more soluble and then reduce the bioavailability of calcium $(\mathrm{Ca})$, magnesium $(\mathrm{Mg})$ and phosphorus $(\mathrm{P})$. Aluminum firstly prevents roots elongation by destroy the cellular structure of the root fungus and subsequently affects the roots uptake of water and nutrients. Meantime, phosphorus is fixed by free iron $(\mathrm{Fe})$ or aluminum $(\mathrm{Al})$ oxides, and $\mathrm{P}$ uptake by roots is reduced. based on a result, $\mathrm{Al}$ toxicity and $\mathrm{P}$ deficiency occur together as two main constraints for crop production in acid soils [19].

A simulated study of the impacts of soil acidic on wheat yield demonstrated that soil acidity could decrease wheat grain yield by up to $60 \%$ on average in alkaline soils, largely due to its calcium carbonate-rich parent material in arid or a dry climate. The alkaline soil's properties are the abundance of carbonates and bicarbonates at $\mathrm{pH}$ above 8.0. Alkaline and calcareous soils occur in 30\% of the earth [1]. Another author reported that under high $\mathrm{pH}$, the bioavailability of plant micronutrients involves as copper $(\mathrm{Cu})$, iron $(\mathrm{Fe})$, manganese $(\mathrm{Mn})$ and zinc $(\mathrm{Zn})$ decreased. Iron deficiency by plants in alkaline soil is a major problem, which leaves become chlorotic and then necrotic, thereby the growth and yielding capacity of the plant are reduced [20]. Update studies showed that iron deficiency can increase the expression of some common genes in roots and leaves while alkaline stress can decrease gene regulation in iron-deficient leaves [1]. Alkalinity not only influences iron and other micronutrient deficiencies but also directly impacts the expression of $\mathrm{Fe}$ absorption genes [21].

Soil nutrient deficiency inhibits plant growth by reducing the bioavailability of nutrients due to low or high $\mathrm{pH}$ [22]. Nitrogen $(\mathrm{N})$, phosphorus $(\mathrm{P})$ and potassium $(\mathrm{K})$ are known as initial nutrients in rice production. Over the past 40 years, the number of $\mathrm{N}$ mineral fertilizers applied for agricultural products has increased by 7.4 times [1]. The recommended application $\mathrm{N}$ is not used effectively, this due to the disappearance of $\mathrm{N}$. Common $\mathrm{N}$ compounds in fertilizer formulations including ammonium $\left(\mathrm{NH} 4^{+}\right)$, nitrate $\left(\mathrm{NO}_{3}{ }^{-}\right)$and urea [CO- $\left(\mathrm{NH}_{2}\right)_{2}$ ]. It was revealed that more than $50 \%$ and up to $75 \%$ of the applied nitrogen is eliminated by leaching into soils [23]. $\mathrm{P}$ is one another nutrient-limited in crop production. Phosphorus deficient soils can be caused by the slow release of inorganic $\mathrm{P}$ from minerals but may be caused more by the low $\mathrm{pH}$ of the soil as mentioned earlier. Moreover, $\mathrm{P}$ is a major determinant of water evaporation, some update studies have shown that $\mathrm{P}$ leaching crucially happens in highly fertile agricultural lands [1]. 
$\mathrm{K}$ plays a crucial role in many plant physiological processes including enzyme activation, stomatal activity, and photosynthesis, uptake of water and nutrients, glucose transport, protein and starch syntheses. Plants mostly show K-deficiency when grown in $\mathrm{K}$ deficient soils, such as sandy soils in rainy areas. General symptoms first appear on the older leaves from light green to yellow, then marginal scorpions and eventually aging [21]. With a severity increase, symptoms can move upwards, leading to a decline in growth and plant performance. Up to date, eight micronutrients are intended to be essential for plants: iron (Fe), zinc ( $\mathrm{Zn})$, manganese $(\mathrm{Mn})$, copper $(\mathrm{Cu})$, nickel $(\mathrm{Ni})$, boron $(\mathrm{B})$, molybdenum $(\mathrm{Mo})$ and chloride $(\mathrm{Cl})$. Deficiency or toxicity of these micronutrients is mostly related to soil $\mathrm{pH}$ or human activities. Salinity conditions which occur mainly in arid and semi-arid regions result from high concentrations of salts dissolved in subsoil or irrigation water. If the electrical conductivity (ECe) of the saturated extract is above $4 \mathrm{dSm}-1$, the percentage of exchangeable sodium below 15 and $\mathrm{pH}$ below 8.5, a saline soil is considered [1]. Salinity and sodicity of subsoil are mostly correlated and related to the parent material of the soil and also enter in the agricultural soil via irrigation or drained water from adjacent areas. Salinity decreases the growth of the plant by physiological drought induced by osmotic stress and specific effects of ions, such as $\mathrm{Cl}$ toxicity and ion concentration imbalance (K, Ca, Mg and Na) [24]. Due to high soil resistance and limiting gas exchange in the rhizosphere, the amount of soil sodicity causes slow roots growth and decreases plant growth. Thus, in saline-sodic soils all of these restrictions act simultaneously to endanger the rhizosphere environments, including the microbial community, thereby reducing crop production [1].

\subsubsection{Biological activities in problem soils and plant growth}

Soil is a complex host for organisms such as bacteria, fungi, actinomycetes, protozoa, and algae, among which bacteria are more represented. As reported, from 108 to 109 cells per gram of soil are existing. The microbial activity in soil significantly influences the soil formation, soil physical-chemical properties, and plant growth. Symbiotic and non-symbiotic bacteria can convert the atmospheric $\mathrm{N}$ into ammonia or other molecules in the body of a living organism, as mycorrhizal fungi improve the plant of $\mathrm{P}$ and $\mathrm{N}$ uptake [25]. However, plant growth-promoting rhizobacteria (PGPR) enhances plant growth, either directly (by facilitating resource availability, modulating plant hormone levels) or indirectly (by reducing the inhibitory influences of various pathogens on plant growth and development) [26]. Plant roots generate specific compounds and molecules that modify the chemical properties of the soil and assist a wide range of organisms. Soil acidity constraints inhibit symbiotic $\mathrm{N}_{2}$, limits the Rhizobium survival and viability of them into the soil, via reducing modulation. As well, salt stress declines symbiosis of Rhizobium with plant in the early stages [27].

\subsection{Plant growth in anthropogenic contaminated soils}

Anthropogenic chemicals in soils of sufficient concentration to cause a hazardous role in human health and ecosystems are known as soil contamination. Contamination is typically caused by industrial activities, the use of agricultural chemicals or the incorrect disposal of waste. Generally, the common pollutants are polycyclic aromatic hydrocarbons (PAHs), heavy metals, chlorophenols, phthalates, and pesticides. According to several recent studies, the effects of organic compounds and heavy metals in contaminated soils on plant growth and production and its associated risks under salinity stress have been well described [28].

\subsubsection{Organic contaminants impact on plant growth}

Soils of agricultural lands may be contaminated by various types of organic pollutants such as PAHs, phthalates, pesticides, and polypropylene diphenyl ethers. Accordingly, the among of organic contaminants of soil which exist the most common of them; PAHs are the group of over 100 hazardous compounds primarily produced by incomplete combustion of organic materials, such as coal, oil, gasoline, and wood. Most of the PAHs nominated enter in the soil after atmospheric and long-term transport [8]. Soil PAHs concentrations have increased over the last 30 years, especially in industrialized areas of the world, and are 
increasing over the next 5 or more years due to the increasing anthropogenic emissions. They are relatively susceptible and tenacious in soils and are less degradable than many other organic compounds [29]. As a result, they are difficult to remove from contaminated soil by conventional treatments. Chlorophenols are used as synthetic intermediates in polymers, dyes, and pesticides or as biocides in a wide range of contaminants. These biocide compounds are a risk to soil microbial communities and may affect soil nutrient turnover and fertility [1]. Some organic pollutants, especially aromatic and organic substances, and chlorophenols are carcinogenic, mutagenic and susceptible to degradation and as a result, have high toxicity to plants and human life. They can have a severe toxic impact on the ecosystem and plant [30]. Furthermore, large volumes of organic dyes, such as blue methylene, orange methylene, orange- $G$ with biodegradation resistance and light stability, tend to destroy DNA structures and threaten environmental health [8] [31].

\subsubsection{Heavy metal contaminants impact on plant growth}

Anthropogenic activities such as mining, smelting, metal waste disposal, lead gasoline and paint, use of pesticides, sludge and fertilizers are responsible for the increase in heavy metal concentrations in soils such as arsenic (As), cadmium $(\mathrm{Cd})$, Lead $(\mathrm{Pb})$, copper $(\mathrm{Cu})$, nickel $(\mathrm{Ni})$, and zinc $(\mathrm{Zn})$. Heavy metal pollution is a global problem but is at a critical level in many countries such as China [1]. Heavy metals at high concentrations impact soil health and biological performance due to their toxicity and consistent after entering in the soil. Arsenic is a carcinogenic element that is toxic and harmful to all living things [32] [ [1]. Plant roots can take up both As (III) and As (V), but As (V) can be easily converted to As (III) in plant cells. Therefore, the growth of rice can be seriously decreased by these substances [32].

\section{Biochar properties and its functionality in problem soils}

Biochar is a pyrogenic carbon or biomass substance that is usually produced from carbon-rich materials, especially agricultural residues [33]. Methods used for the production of biochar include pyrolysis, gasification, hydrothermal carbonization, and flash carbonization [8]. The pyrolysis temperature alters from $200{ }^{\circ} \mathrm{C}$ to $1,000^{\circ} \mathrm{C}$, and its duration can be a fast or slow process, nevertheless, slow pyrolysis is preferred for biochar production [34]. Differences in chemical and physical properties of biochar mainly depend on the type of feedstocks, methods of production and temperature [35] [36]. Under special conditions, biochar produced from toxic solid waste may present secondary pollution hazards [1]. However, most of the biochars are beneficial to soils as amendments [37] [38]. The function and properties of biochar are summarized in (Figure1), which include surface area and porosity, surface function group, exchangeable cations, and organic $\mathrm{C}$ and $\mathrm{N}$ compounds.

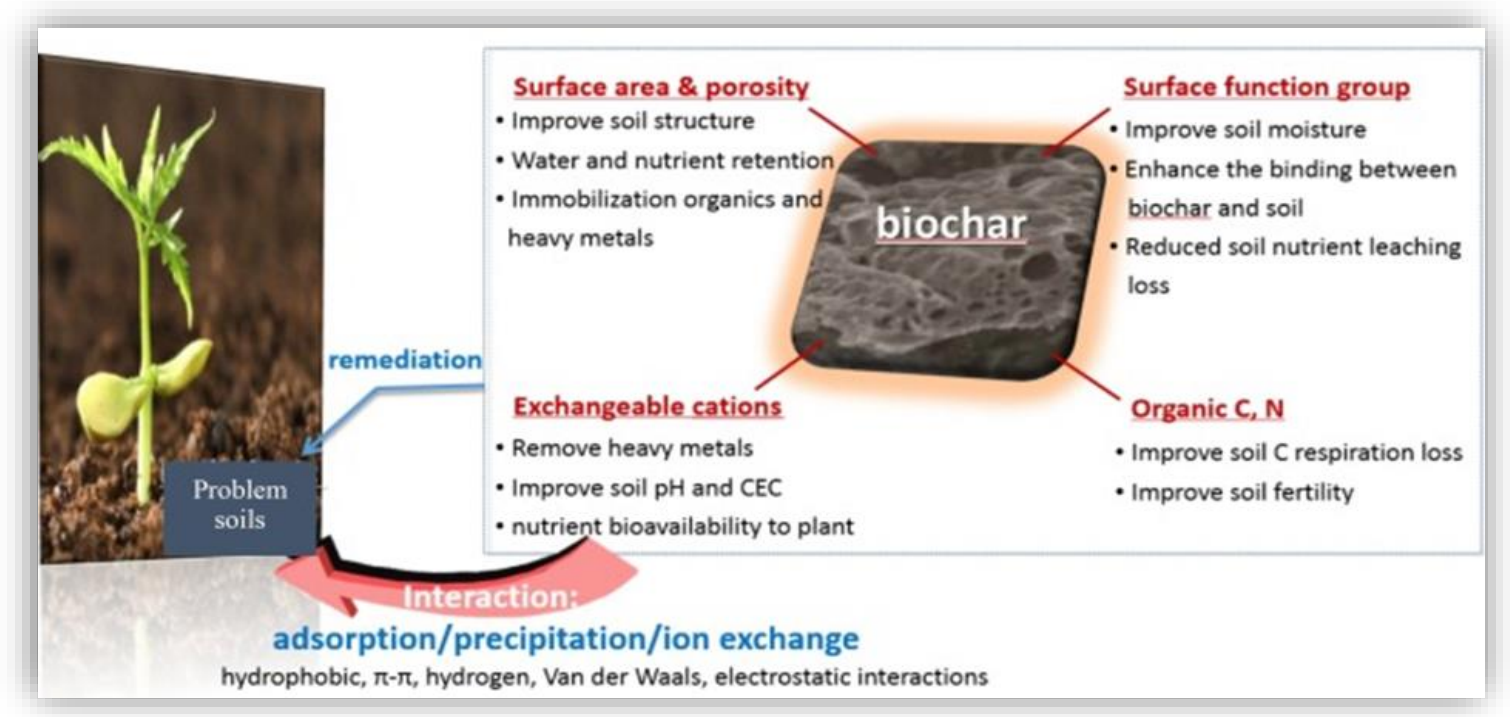

Figure 1: main physical/chemical biochar properties and its functionality in problem soils and crop production [1], and further details of figure the below subheadings are presented. 
The role of surface area/porosity of biochar relates to the soil structure improvement, water and nutrient retention, immobilization organics and heavy metals. The surface function group is of great importance for improving soil moisture, enhancing binding between biochar and soil, and reducing soil nutrient leaching loss. Therefore, the exchangeable cations feature has a great influence to remove heavy metals, improve soil $\mathrm{pH}$ and CEC, and nutrient bioavailability to plant. The organic carbon and nitrogen in biochar compounds can play a key role in ameliorating soil C respiration-loss and soil fertility [1].

\subsection{General physical properties of biochars}

Biochar physical properties mainly include; (i) Density and porosity, (ii) surface area, (iii) pores volume and size, and (iv) hydrophobicity and water holding capacity [36]. Different terms have been used for explanation biochar density, such as words of bulk density (volume-specific weight), particle density (consider only solid and closed pores into accounts), envelope density (take the solid structure, all pores and surface irregularities into accounts), skeletal density (solid density without intradoses) and actual density (consider solid structure only) [39]. Most of the biochars have a relatively low bulk density of below at $0.6 \mathrm{~g} / \mathrm{cm} 3$ [1]. In the case of biochar derived from woody-materials under the pressure of the atmosphere, the porosity range varies from about $50 \%$ at $300^{\circ} \mathrm{C}$ to $70 \%$ at $850{ }^{\circ} \mathrm{C}[40]$. Biochar produced from grass shows that porosity increases in the temperature rate of $350-700{ }^{\circ} \mathrm{C}$ [1].

However, hydrophobicity-feature is linked to the surface functional groups, although the water holding capacity is reliant on the porosity of biochars' bulk volume [41]. The surface area is closely related to the emission of volatile gases during carbonization. Thus, several studies have proven that functionalities of biochar can depend on the pores, surface functional group, free radicals, and structure of biochar production processes [2]. Pores are generally classified as macropores $(0.05-0.002 \mu \mathrm{m})$ and micropores $(0.05-0.0001 \mu \mathrm{m})$ by a diametric method (diameter $0-0.05 \mu \mathrm{m})$ [36]. The pore volume is closely correlated with the surface area, and the total pore volume increases when pyrolysis temperature increases. Many different methods have been used to measure pore volume, and results may vary significantly with the measurement methods. The reduction of the surface functional group due to the increase in the pyrolysis of temperature and shifts the affinity to water [41]. On the other hand, there is a hypothesis that proliferating in temperature make increases biochar porosity and also promotes water absorption capacity. Notwithstanding the importance of the two factors, their relationships in water retention have not been well studied. Researchers highlighted that higher temperatures resulted in less water being absorbed onto the biochar inner surface [1].

\subsection{General chemical properties of biochars}

General chemical properties of biochar include (i) $\mathrm{pH}$, (ii) cation exchange capacity, (iii) atomic ratios, primarily $\mathrm{O} / \mathrm{C}$ and $\mathrm{H} / \mathrm{C}$, and (iv) elementary composition. Overall, the biochar $\mathrm{pH}$ ranges from 5.9 to 12.3, by an average of 8.9 [42]. While increasing the temperature of pyrolysis, biochar cation exchange capacity and $\mathrm{pH}$ increase, but $\mathrm{O} / \mathrm{C}$ and $\mathrm{H} / \mathrm{C}$ ratios decrease [1]. This may indicate that some are different from the dried gases produced, the biochar produced by dry pyrolysis through hydrothermal carbonization include the formation of organic acids and thus acidic hydrocarbons [3]. The building-block elements of biochar during the pyrolysis experience different Physico-chemical processes and form different species and products [37]. The basic chemical elements contain: $\mathrm{C}, \mathrm{H}, \mathrm{O}$ and $\mathrm{N}$. The percentages of $\mathrm{P}, \mathrm{S}$, and $\mathrm{Si}$ accessibility, as well $\mathrm{Fe}, \mathrm{Cu}, \mathrm{Zn}$, and $\mathrm{Mn}$ are depended on different biochars [4]. Carbon is the most important part of the biochars body-structure (carbonate and bicarbonate in aliphatic and inorganic carbon). $\mathrm{H}$ as an important build-structure of biochar may play an important role in the absorption of biochar into ionizable molecules [37]. Oxygen occurs in organic and inorganic phases. Plant organs particularly leaves, and herbaceous species are mainly rich in $\mathrm{N}$, which are happening in the form of proteins, amino acid, pyrrolic, and pyridine [1]. At the time of pyrolysis, the Peptide-N bonds were transferred to $\mathrm{N}$-heteroaromatic carbon composites, and the amount of Amide-N within the biochars reduced with increasing pyrolysis temperature. The $\mathrm{N}$ doping has been used to amend the electronic band 
structures, which could recover $\mathrm{N}$-doped biochars in sorption and catalysis capacities [34]. However, $\mathrm{P}$ contents in plants are different (from $0.1 \%$ to $1.0 \%$ ). The stabling of $\mathrm{P}$ during the pyrolysis is under $700{ }^{\circ} \mathrm{C}$ and will not be volatilized. The pyrolysis of transformed organic $\mathrm{P}$ to inorganic $\mathrm{P}$, resulting in the $\mathrm{P}$ enrichment of biochars, as a type of $\mathrm{P}$ - enhancing could be a $\mathrm{P}$ source for plant growth. Furthermore, $\mathrm{P}$ in biochars could get the responsibility of linking heavy metals through precipitation. For example, during the pyrolysis and gasification of oak and corn biomass, total $\mathrm{P}$ is increased. Pyrolysis produces sulfate, organosulfur, and sulfide through gasification results in 73-100\% organosulfur [1]. Sulfur-enriched biochar could be a potential soil amendment and fertilizer, so a massive range of crops, such as rice, barley, maize, and wheat require $\mathrm{Si}$ for growth, and biochars pyrolyzed from these plants generally contain high concentrations of Si. Thus, the Si content in biochars made from rice-straw increased from $6.16 \%$ when pyrolyzed at $150{ }^{\circ} \mathrm{C}$ to $18.29 \%$ pyrolyzed at $700{ }^{\circ} \mathrm{C}$ [2]. However, $\mathrm{Si}$ in biochars is shown to provide to the sorption and upkeep of heavy metals, such as $\mathrm{Al}$ and $\mathrm{Cd}$ [43]. The over-tendency for $\mathrm{P}, \mathrm{Si}, \mathrm{S}, \mathrm{K}, \mathrm{Ca}, \mathrm{Mg}$, $\mathrm{Fe}, \mathrm{Cu}, \mathrm{Zn}$, and $\mathrm{Mn}$ are, by increasing the temperature of the pyrolysis, the contents of these elements in the biochar are increased, but their bioavailabilities are reduced. This event related to the presentation elements into the highly aromatic structure of biochar at higher pyrolysis temperature. The low-temperature pyrolysis has been contributing to improve the bioavailability of these nutrient elements. For example, derived biochar from maize-straw is showed that $\mathrm{K}$ exchangeability in the pyrolyzed at 300 and $400{ }^{\circ} \mathrm{C}$ was more accessible to the roots of the plant than those pyrolyzed at $500{ }^{\circ} \mathrm{C}[44]$

\subsection{General surface and functionality of biochars}

Biochar surface is attributed to the interfaces of the various chemical and biological activities performed. Based on several recognized studies, the surface functional groups, surface charge, free radicals, and structure are related to the functionality of biochar [2]. Besides aliphatic and aromatic groups, biochar surfaces are carboxyl, hydroxyl, epoxy, acyl, carbonyl, ether, and ester, amido, sulfonic, and acyl groups. Different methods have been used to measure these groups including Fourier transform infrared (FTIR) spectrometry, X-ray photoelectron spectroscopy (XPS), X-ray refraction (XRD), solid-state 13C nuclear magnetic resonance (NMR), and Raman spectroscopy [8] [45]. The most abundant groups are phenolic$\mathrm{OH}$, carboxyl, carbonyl, and ester groups, for this reason, these groups can associate/dissociate with protons in the environment, hydrogen bond induction absorption, alkalis of biochar, $\mathrm{pH}$ buffering, hydrophobic/hydrophobicity, alternating surface charge, cations exchange capacity (CEC), and electrovalent improvement [37]. Moreover, functional groups are complete sites in the chemistry surface, and chemical modification of biochars, including oxidation, amination, and sulfonation [8].

The surface charge of the biochar has an aliphatic or aromatic surface and the change of functional groups such as carboxyl groups is strongly associated with the level of $\mathrm{pH}$ in the solution. Many ion-exchange places for the absorption and desorption process of nutrients are attributed to carboxyl groups and heavy metals, play important roles in buffering $\mathrm{pH}$ [1]. As also free radicals are begotten during the carbonization. Due to the increasing pyrolysis temperature, radical types are transitioned from oxygen-centered radicals to collective carbon-centered and oxygen-centered radicals where atoms of aromatic carbon are stabilized on the surface, free radicals due to their rich-electron in the aromatic surface. It was reported that free radicals in biochar prevent seed germination and plant growth [30] [1]. The related study revealed that free radicals play significant roles in the degradation of organic pollutants; this may due to their reactions with hydrogen peroxide and persulfate [37]. However, biochar $\mathrm{pH}$ plays an important role in the surface charge, which is dictated to be indirectly attributed to the $\mathrm{O}$ contents of the functional groups. Many of the functional groups usually exist on the surface of biochars exhibit amphoteric properties, and it can depend on the reactivity and electronegativity of the environment $\mathrm{pH}[11]$. 
Anwari et al., Adv. J. Grad. Res.; Vol. 7, Issue 1, pp: 45-63, January 2020

\section{Biochar amendment improves soil problems and properties}

Biochar as a natural organic and rich- $\mathrm{C}$ matter containing carbon percentage is about $60-80 \%$, with a high active surface area and functionality. Biochar amendments improve not only physical, chemical and biological properties of soils but also support plant growth and ameliorate soil problems [1].

\subsection{Biochars improve naturally soil problems}

\subsubsection{Physical properties improvement}

Biochar generally reduces soil density, both (bulk density and particle density) in amended soils [46]. This decrease is largely attributed to lower bulk density $\left(0.6 \mathrm{~g} \mathrm{~cm}^{-3}\right)$ and lower particle density $\left(1.5\right.$ and $2.0 \mathrm{~g} \mathrm{~cm}^{-}$ 3) of biochar than to bulk density $1.25 \mathrm{~g} \mathrm{~cm}-3$ and particle density $2.4-2.8 \mathrm{~g} \mathrm{~cm}^{-3}$ of soil. It may also improve the integration and porosity associated with the integration of biochar with soil. An analysis performed by Omondi [17] showed that biochar amendment significantly improved the physical properties of the tested soils by soil bulk density decreased $7.6 \%$, soil porosity reduced $4.8 \%$, total stability increased $8.2 \%$, availability of water holding capacity (AWC) increased $15.1 \%$, and hydraulic conductivity increased $25.2 \%$. In recent years published articles have been indicated that on average; the biochar application reduced bulk density by $12 \%$. Bulk density of sandy soils is more influenced by the application of biochar than clay soils because the bulk density of sandy soils is $1.5 \mathrm{~g} \mathrm{~cm}^{-3}$ compared to $1.1 \mathrm{~g} \mathrm{~cm}^{-3}$ for clay soils. Biochar application could improve the compaction problem of soils by more than $10 \%$. The decrease in soil bulk density and particle density is negatively correlated with soil porosity. Liu, [47]demonstrated that biochar amendment increased soil porosity up to $8.4 \%$. The soil porosity increase is due to in part to the porosity of biochar (70-90\%). It also contributed to (i) reducing soil bulk density, (ii) increasing soil accumulation, (iii) interacting with mineral soil particles, and (iv) reduction of packing [38]. The decrease in bulk density and increase in soil porosity can improve the movement of water, heat, and gases into soils. In a modified sandy soil with biochar, discovered that after draining the gravitational moisture, the biochar filled and retained water in its pores, which reduced water permeability and increased water retention in clay soil [47]. Many authors believe that the higher resistivity of clay aggregates is due to the enhanced internal cohesion through the interaction of mineral particles and carbon bonds, and the improvement of soil water retention by the number of macropores and mesopores in clay soils by biochar [1].

The benefits of biochar application on soil physical properties have been extensively investigated by BlancoCanqui, additionally, for reducing bulk density and particle size and increasing porosity, the application of biochar improves soil texture quality and soil aggregation. The altering of saturated hydraulic conductivity and reducing saturated water flow in coarse soils and increase it in fine-grained soils is related to the high ability of biochar [39]. However, information on the use of biochar for salt-affected soils problem is limited. It is generally accepted that soil organic carbon accumulation is necessary to improve soil properties. Biochar is a rich carbon and organic materials with unparalleled properties, we agree with the hypothesis that the physical properties of soil problems, especially in salinity conditions could benefit more from biochar application than highly fertile or productive soils. Future research on salt-affected soil challenges is expected to confirm this hypothesis.

\subsubsection{Chemical properties improvement}

Biochar application in soil problems showed a significant improvement in chemical properties. Since soil acidification is a growing problem worldwide, biochar application can alleviate soil acidity. This effect has been attributed to several factors such as 1) biochar alkalinity 2) high $\mathrm{pH}$ buffer capacity 3) function group effects and 4) Si effects [1]. The investigated study has shown that $\mathrm{pH}$ increased in a highly acidic Ultisol with high alkalinity $\left(\mathrm{R}_{2}=0.95\right)$ compared to the bioactive biochar $\mathrm{pH}\left(\mathrm{R}_{2}=0.46\right)$. Mineral elements include calcium $(\mathrm{Ca})$, potassium $(\mathrm{K})$, magnesium $(\mathrm{Mg})$, sodium $(\mathrm{Na})$ and silicon $(\mathrm{Si})$ in the feedstocks form carbonates or oxides during the biochar pyrolysis, which reacts with $\mathrm{H}$ and monomeric $\mathrm{Al}$ species in acidic soils by decreasing interchangeable acidity and increasing $\mathrm{pH}$. Moreover, to carbonates and oxides in 
resultant alkalinity biochar, functional groups like $-\mathrm{COO}-$ and $-\mathrm{O}-$ also contributed mainly to biochar alkalinity whenever pyrolyzed at lower temperatures $\left(300-500{ }^{\circ} \mathrm{C}\right)$ [38]. Some results have suggested that the total base cations concentration is correlated with the amount of alkalinity, which can be used as a predictor of total alkalinity in the biochar in a study on acid soils at pH 4.96 [48]. Accordantly, in four amendment biochars produced from corn-straw, canola-straw, rice-straw, and peanut-straw, $\mathrm{pH}$ could increase from 4.96 to $6.69,6.78,7.45$ and 8.40 and soil $\mathrm{pH}$ buffering capacity from 12.52 to $23.33,23.14$, 30.49 and $37.37 \mathrm{mmol} \mathrm{kg-1} \mathrm{pH}-1$, respectively. The increase in $\mathrm{pH}$ buffer capacity mainly due to the increased cations exchange capacity (CECs) after biochar application [49]. Meanwhile, the release of cations $(\mathrm{K}, \mathrm{Ca}, \mathrm{Mg}$ and $\mathrm{Na}$ ) from biochar was the major cause of the increase in $\mathrm{pH}$. The propagation of the action is due to the propulsion of carboxyl groups at the biochar surfaces and the dissolution of carbonates [47]. Comparatively, biochar among different materials that are applied for neutralizing soil $\mathrm{pH}$ can persist in soils for a long period, thus maintaining soil $\mathrm{pH}$ at a desirable level [49]. There is finite information on the use of biochar in alkaline soils. Based upon reviewed conclusion, the application of biochar derived from locusts (Robina spp.), and Chinese pine (Pinus spp.) with ( $\mathrm{pH}$ 8.38), into alkaline soils (4, 8 and $16 \mathrm{~g}$ biochar $/ \mathrm{kg}$ of soil) collected from the Loess Plateau ( $\mathrm{pH} 8.66$ to 9.0, slightly higher than of the biochar), shown that biochar application could decrease soil $\mathrm{pH}$ in up to 0.2 units after 4 months of incubation. The decrease in $\mathrm{pH}$ may be in the result of acid production due to acid oxidation depending on the carbonation temperature that acidic biochar could produce. Use of acidic biochar in alkaline soils may improve alkaline soil $\mathrm{pH}$ [50]. It was shown that by producing acidic biochar at $\mathrm{pH} 5.8$, and applied to a worn calcareous soil, the $\mathrm{pH}$ decreases between 0.2 and 0.4 units, while the bioavailability of $\mathrm{P}, \mathrm{Mn}$, and $\mathrm{Zn}$ increases. For acidic biochars production and their application to improve alkaline soils further investigations are required. Biochar application can increase the fertility of challenging soils. For example, biochars found in rice or other grass feedstocks are known for large amounts of Si. Soybean-derived biochars contain large amounts of $\mathrm{N}$; derived eggshell biochars are high in $\mathrm{Ca}$ and manure biochars produced are rich in nutrients. Due to different properties in different precursors, they can allow biochars to be selectively selected as specific elemental fertilizers [51]. One of the biochar fertilizer characteristics is that the nutrients are released slowly, mediated by unique biochar structures and the absorption-disposal process. Porous sizes and networks within the biochar create some constructive or physical barriers that prevent nutrients from being released easily. The functional groups of biochar with a strong sorption capacity can insert nutrients into the soil's problems, and thus allow absorption into the aqueous phase for plant uptake slowly [1] [51]. Characteristics of saline and sodic soils are attributed to their higher ECE, ESP, and $\mathrm{pH}$ low values.

\subsection{Biochars improve soils problem with anthropogenic contaminants}

\subsubsection{Heavy metal polluted of soils}

Toxicity of heavy metals is the biggest threat to global agricultural productivity that pollutes in the soil and water of paddy-fields and environment, and also known as a major threat to food security and food safety. The levels of these metals/metalloids in rice grains are rising and cause serious concerns for human health. Heavy metal accumulation greatly decreases appearance growth and yield of rice by reducing photosynthesis, disrupting cellular organs, lipid composition, protein synthesis, and nutrient homeostasis due to increased ROS production causing oxidation stress and up - and down-regulation of the genes involved in antioxidant defenses [51]. Biochar with the great surface area, plentiful pore volume, and rich functional groups is alleged to have a large capacity for sorption of heavy metals [52]. So, Lian [34]suggested that heavy metal uptake on biochar can be mainly specified via the interaction of electrostatic and adsorption precipitation between the heavy metals and functional groups of biochar. Therefore, the association of the adsorption and capacity of the heavy metals in the surface area and pore volume relies more on the surface functional groups. Based on Qian study [53], the oxidation treatment introduced carboxylic functional groups on the biochar surface and this increased the adsorption capacity for $\mathrm{Al}_{3}$ because the existing oxygen group acts as coordinated sites for $\mathrm{Al}_{3}$. Besides, ion exchange, ligand metal composition, cations binding, and surface coprecipitation can also contribute to biochar's heavy metals 
Anwari et al., Adv. J. Grad. Res.; Vol. 7, Issue 1, pp: 45-63, January 2020

uptake [54]. Taking $\mathrm{Pb}^{+}$as an example (Figure 2), it proposed that the synergistic effects of $\mathrm{Pb}^{+}$sorption on biochar surface are due to 1) heavy metals exchanges with cations $\left(\mathrm{Ca} 2^{+}, \mathrm{Mg}^{+}\right)$of biochar, 2) heavy metals interactions with different functional groups on biochar surface, and 3) other unspecified adsorption processes [1]. It was also found that the adsorption $\mathrm{Cd}$ on biochars is mainly implemented by the ion exchange [34].

In general, low- and medium-temperature pyrolyzed biochars can have the highest adsorption capacity for metal cations. For other inorganic anionic contaminants, such as $\mathrm{F}-, \mathrm{ClO}_{4}-, \mathrm{PO}_{43}-, \mathrm{Cr}$ (III) and $\mathrm{Cr}(\mathrm{VI})$, their adsorption by aromatic and hydrophobic surfaces of biochars increases at higher polarized temperatures [37]. Biochar can strongly decrease the availability and bioavailability of heavy metals in the soil directly to other physicochemical reactions [8]. For example, biochar application caused the chemical reduction of $\mathrm{Cr}(\mathrm{VI})$ to $\mathrm{Cr}(\mathrm{III})$ and precipitation of $\mathrm{Cr}(\mathrm{OH})$, consequently, it can be said that heavy metals are conveyed to the grain of rice through agricultural inputs (chemical fertilizers, pesticides, irrigation water, etc.). Heavy metal pollutants in soil negatively affect soil biological properties and physical performance by disturbing soil biological and physiological characteristics such as poor soil health (structure and productivity) and low soil microbial activity. But the combination of a large amount of biochar in the soil increased the habitat of the microbial population by increasing the porosity [55]. Additionally, biochar can donate or accept electrons in its environment through biological pathways. Biochar is the soil also can promote microbial electron shuttling processes that are similar to soil organic matter with active redoxactive groups for the reason that of several other factors, such as $\mathrm{pH}$, reduced the solubility of heavy metals, improved microbial biomass, and nutrient recovery [1] [55].

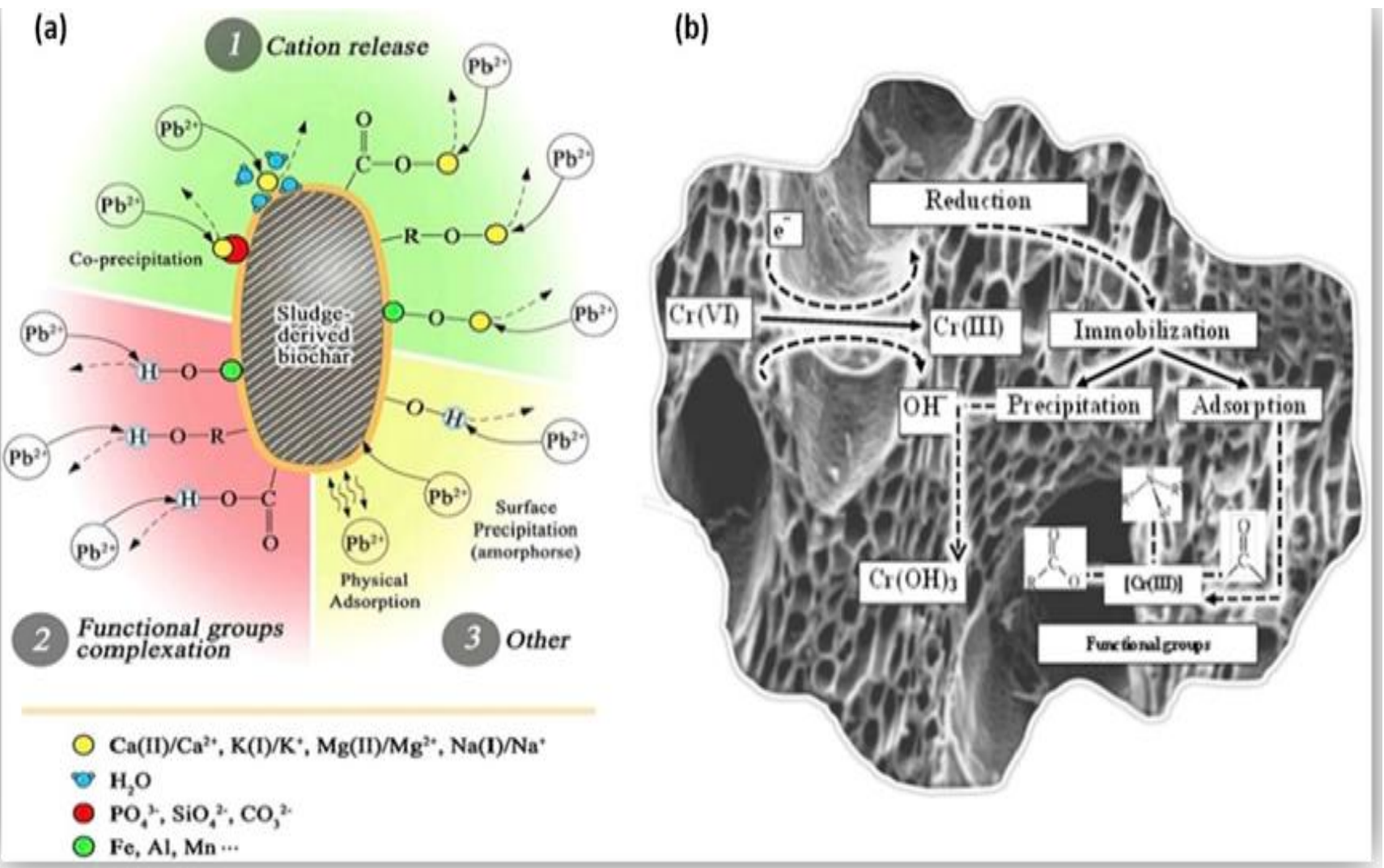

Figure 2: Mechanisms Pb adsorption (a) on the biochar and (b) reduction on immobilization of chromium in soils by biochar application of derived sludge materials [56].

\subsubsection{Organic polluted of soils}

Biochars with the electronic interactions ability could able to absorb both hydrophilic and hydrophobic organic compounds [57]The relative carbonized (for adsorption) and noncarbonized (for partition) fractions determine its adsorption behavior for organics. The adsorption shows that the nonlinear 
isotherms and competition with the organism's symbiosis, whereas partitioning is a linear and noncompetitive process [34]. For example, derived wood pulp was used to leach three representative organic pollutants, persistent hydrocarbon (phenanthrene), a herbicide (isoproturon), and an antibiotic (sulfamethazine), the sorption results suggested that $5 \%$ biochar added to soil increased the partitioning coefficient factors by 20 for both sulfamethazine and isoproturon, and 2 for phenanthrene, respectively [57]. Biochars can degrade and redox organic compounds due to the graphical and (semi) quinone structures that can accept and donate electrons and also free radicals generated in the biochar production process. The free radical can degrade P nitrophenol, 2-chlorobiphenyl, and diethyl phthalate [34]. Biochar contains a portion of the colloidal and soluble $\mathrm{C}$ that have a high capacity for absorbing PAHs than bulk biochars. As YU evaluated [1], that the only high-carbonaceous and surface of biochar materials have beneficial effects on stabilizing contaminated soil with organic compounds includes sulfamethazine. Researchers also recognized that ball-milled sugarcane bagasse biochar had a greater methylene blue sorption compared with the common biochars because the ball-mill method had more beneficial for the increasing of external/internal surface areas exposed and oxygen-containing functional groups of the biochar. The obtained graphitic structure increases methylene blue adsorption via electrostatic attraction and $\pi-\pi$ interaction [58].

\subsection{Biological properties improvement}

Biochars as modifiers can create favorable environments for microbes in soil difficulty, especially in saline conditions. Application of biochar at the range of $10 \mathrm{t} / \mathrm{ha}$ or higher, resulted in a significant increase in biological fixation of nitrogen by red cloves (Trifolium pratense L.) when compared to control [59]. Biochars composition in soil positively affected Arbuscular mycorrhizal fungi, and recently, PGPRs including Aeromonas hydrophila, A. caviae, and Bacillus isolates have been shown to improve plant growth in salt-affected soils. PGPRs can secrete exopolysaccharide that binds $\mathrm{Na}^{+}$and reduces its uptake in plants, however, some PGPRs contain a vital enzyme called 1-aminocyclopropane1-carboxylate (ACC) deaminase, which plays a vital role in relieving salinity stress in plants. Biochar amendment with the PGPR could alleviate the salt-stress in the maize either by reducing the xylem $\mathrm{Na}$ concentration or by maintaining nutrient balance within the plant. Besides PGPR, endophytic PGPRs can colonize the internal tissue of the plant (instead of only in rhizosphere) without causing any symptomatic infection [59].

Fungi and bacteria use their extracellular enzymes to degrade layers involve biochar derived-C into smaller molecules which can be taken up into their cells and used for different metabolic activities [9]. Microbial biomass- $C$ is considered as an indicator of any changes in soil organic $C$ content and decomposition. Therefore, any processes and materials that alter $\mathrm{C}$ content in soil can affect biomass and activity of the microbial community. Biochar application to soils improved Arbuscular mycorrbizal (fungi) to colonize plant roots and surface porosity, and micropores habitats are believed to play an important role in improved mycorrhizal interaction with plant roots [1] [60]. Moreover, many researchers explained biochar application can protect the cell, and the integrity of rice tissues by reducing the damage of the cell membrane caused by sodium ion stress.

\section{Biochar amendment in soils problem and rice growth under salinity conditions}

Rice (Oryza sativa L.) as the world's second-largest crop in terms of consumption and production. Scientists conduct many different kinds of research to find out some affordable methods for reducing soil problems (salinity, sodicity, acidity, alkalinity, and pollution-stresses) annually. However, among different methods and remediation materials that have explored yet, the biochar amendment as significant alternative matters could be considered an affordable solution manner for increasing soil fertility and rice productivity. The evidence indicated that biochar remediation roles can be improved soil health and increase rice yielding capacity in soil problems (Table 1). 
Anwari et al., Adv. J. Grad. Res.; Vol. 7, Issue 1, pp: 45-63, January 2020

Table 1: Different biochars amendment effects on the increasing percentage (\%) of rice yield in soil problems, and particular in salinity conditions.

\begin{tabular}{|l|l|l|c|c|}
\hline \multicolumn{1}{|c|}{$\begin{array}{c}\text { Naturally } \\
\text { Poor soil type }\end{array}$} & \multicolumn{1}{|c|}{ Biochar Type } & Plant & $\begin{array}{c}\text { Growth/Yield } \\
\text { Increases (\%) }\end{array}$ & Reference \\
\hline Sandy soil & Wood & Rice & 20 & {$[61]$} \\
\hline Acid soil & Sewage sludge & Rice & $148.8-175.1$ & {$[56]$} \\
\hline Saline soil & Bamboo & Rice & 20 & {$[62]$} \\
\hline Waterlogged paddy soil & Rice husk & Rice & 12 & {$[60]$} \\
\hline $\mathrm{Cd}, \mathrm{Pb}$ & Wheat straw & Rice & $16.6-18.3$ & {$[63]$} \\
\hline Poor sandy loam soil & Rice straw & Rice & 12.3 & {$[64]$} \\
\hline Saline-sodic paddy soil & Wheat straw & Rice & 13.4 & {$[65]$} \\
\hline Saline-sodic paddy soil & Peanut shell & Rice & $22.45-23.81$ & {$[66]$} \\
\hline
\end{tabular}

\subsection{Biochar improves rice growth in soil problems with physical constraints}

The main hindrance to plant growth in soil with physical constraints is the roots establishment and its growth. Xiang [67] reported biochar application could increase in an order; roots biomass by $32 \%$, roots volume by $29 \%$, surface area by $39 \%$, root length by $52 \%$, number of roots tips by $17 \%$ and root diameter by $9.9 \%$, respectively [67]. These data indicated that roots can establish in a better condition into soil problems by application of biochar-amended and as a result, the development and growth of roots increase significantly. The increasing root's parameters can expand the volume of roots in the soil for capturing more nutrients and therefore improving plant growth [1]. Furthermore, a similar study showed that biochar application significantly increased rice yield (Table1) by reducing $\mathrm{Na}^{+}$concentration $\left(\mathrm{Na}^{+} / \mathrm{K}^{+}\right.$ratio) and increasing $\mathrm{K}^{+}$concentration. As well, the same study revealed that the use of biochar had a significant influence on increasing leaf water status, plant height, and chlorophyll content index by decreasing the leafrelative electrical leakage in rice [66]. Moreover, another researcher reported that biomass production and harvested yield significantly increased, and salt-stress reduced by biochar application in saline-sodic paddy soils [65].

\subsection{Biochars improve rice growth in acid soils}

Acidic soils generally have lower fertility due to the increased availability of $\mathrm{Al}$ and $\mathrm{Mn}$ and decreased $\mathrm{P}$, $\mathrm{Ca}$, and $\mathrm{Mg}$. It seems that the amendment of biochar in acid soils improves soil quality and crop growth. Application of two biochars derived from a paper-mill to a ferrosol, at $10 \mathrm{t} \mathrm{ha}^{-1}$ increased $\mathrm{pH}$ from 4.2 to 5.4 and 5.9 respectively; soil CEC, exchangeable $\mathrm{Ca}$, and dry weights of radish, soybean, and wheat increased significantly [68]. In the resulting of availability of the high $\mathrm{pH}$ buffering capacity and alkalinity characteristics of biochars, especially those biochars pyrolyzed at high temperatures could neutralize or partially reduce the soil acidity [38]. Biochar amendment can decrease exchangeable sodium percentage (ESP) and increase the water-stable aggregate percentage; therefore, the enhanced plant growth and decreasing Na uptake by rice and maize plants observed were due to biochar application effects on reducing salt stress [69]. Thus, Table 1 has shown that the rice yielding capacity significantly increased after biochars application in different saline-sodic soils [38] [70] [62] [65] [69]. As well, related studies reported that the application of biochars derived from Sewage-sludge in acid soils enhance rice productivity by $148.8 \%$ to $175.1 \%$ based on either biomass or yield [56].

\subsection{Biochar improves rice growth in alkaline soils}

Alkalinization is the process of increasing the concentration of $\mathrm{Na}$ ions in the exchange of complexions in the soil. This method is enhanced by other soluble salts, such as $\mathrm{Mg}$ and $\mathrm{Cl}$, minerals as gypsum are collected closer to the soil surface [71]. Generally, the creation of alkaline soil is linked to geological, geographical and climatic conditions. Human activities such as irrigation, fertilization, poor drainage systems, and inadequate farming accelerate the process. Most alkaline soils are found in areas that have the greatest 
potential for agriculture because these soils are easily irrigated and cultivable. Year after year, the continuous impact of salt on the soil results in soil organic matter material depletion, loss of crop productivity, and soil degradation [72]. Although the information on the modification of alkaline soils by using biochar is not enough, some important reports indicate the positive effect of acidic biochar on soil modification and plant growth under alkalinity conditions. Since nitrate leaching and biochar application without reduction of soil $\mathrm{pH}$ are the main concern on crop production. A study on nitrate leaching and plant growth in a calcareous sandy soil (pH: 7.9), with biochar ( $\mathrm{pH}: 6.65)$ derived from maize straw reported that biochar application increased soil organic matter and $\mathrm{N}$ use efficiency [73]. Fruit fresh weights of zucchini (Cucurbita pepo L.) increased by $26.7 \%, 55 \%$, and $195 \%$ when grown in the soil amended with three rates of the biochar. Researchers believe that increasing the yield of zucchini plant in alkaline soil by using biochar is due to improved soil organic matter content and increased $\mathrm{N}$ and P efficiency (3.6/0-2.2). Biochar is suggested as a phosphate fertilizer source for recycled calcareous sandy soils due to its high content of P $(0.6 \mathrm{~g}-3.2 / \mathrm{kg})$ [74].

\subsection{Biochar improves rice growth in nutrient-deficient soils}

Biochar improves rice growth in the soil's problem and nutrient-deficient. Plants grown in soils with a nutrient deficiency will hold deficiency, symptoms have appeared in both physiologically and morphologically. Its effects range from immediate disruption of root growth or widespread disruption to the membranes or cell wall to changes in the cytosol $\mathrm{pH}$, due to reduced carbohydrate export, or the inability of an enzyme to properly align with a reactant. Consequently, each of these can lead to oxidative stress (photoinhibition and photooxidation) the final destruction of chloroplasts and symptoms that we know as chlorosis and necrosis [75]. Biochar amendment use on nutrient-deficient soils has been shown to improve plant growth, including rice, corn, common beans, lettuce, and oats, the increasing plant growth can be attributed to the following three factors: i) nutrient supply by biochars, ii) increased nutrient utilization efficiency and iii) optimal rhizosphere environment. The contents of the elements in biochar are very relevant to the feedstocks and the carbonation processes and methods of production. Generally, the low pyrolysis temperature $\left(250-300{ }^{\circ} \mathrm{C}\right)$ is superior for the soil amendment as more nutrient elements could be maintained [1]. Gunes [76], showed that the total concentrations of $\mathrm{P}, \mathrm{K}, \mathrm{Ca}, \mathrm{Mg}, \mathrm{Fe}, \mathrm{Zn}, \mathrm{Cu}, \mathrm{Mn}$, and B increased with increasing gas temperature, but the water-soluble concentration of these elements except $\mathrm{K}$ and B decreased. As lettuce and corn ripened in clay loam soil and biochar significantly reduced dry weight compounds compared to untreated control. The dry weight increase was associated with increased $\mathrm{P}$ and $\mathrm{K}$ contents in both plants compared to the control, while leaves tissue contents of $\mathrm{Ca}, \mathrm{Mg}, \mathrm{Fe}, \mathrm{Mn}$, and $\mathrm{B}$ in lettuce plants decreased. $\mathrm{Zn}$ in maize increased by the biochar treatments. The variable content of calcium $(\mathrm{Ca})$, magnesium $(\mathrm{Mg})$, iron $(\mathrm{Fe})$, manganese $(\mathrm{Mn})$, boron $(\mathrm{B})$ and zinc $(\mathrm{Zn})$ in different plants may indicate that biochars can serve as a reservoir for regulating plant's need for specific nutrients. Co-application of biochars with inorganic or organic fertilizers enhances plant nutrient use efficiency [76] [1]. The result of biochar application in the low fertile soil of paddy-field shown that biochar could plant sodium uptake reduced by transient $\mathrm{Na}^{+}$binding due to its high adsorption capacity and by releasing mineral nutrients particularly $\left(\mathrm{K}^{+}, \mathrm{Ca}_{2}{ }^{+}, \mathrm{Mg}_{2}{ }^{+}\right)$into the soil solution [55]. Based on many results, the application of biochar in low nutrients soils with a rate of 3 tons/ha was shown that grain weight per panicle, the number of spikes and 1000-grain weight were significantly increased. The $\mathrm{N}$ contents of root and shoot increased. Also roots and shoots content of $\mathrm{N}$ can increase $\left(\mathrm{K}^{+}, \mathrm{Ca}^{+}, \mathrm{Mg}^{+}\right)$into the soil solution by using biochar [77].

\subsection{Biochar improves rice growth in salt-affected soils}

Biochar application on the salt-affected soil report has shown that salt-stress reduces, and plant growth improves significantly. Plant growth is directly correlated with the release of essential plant nutrients such as $\mathrm{K}, \mathrm{Ca}, \mathrm{Mg}, \mathrm{Mn}, \mathrm{Cu}$, and $\mathrm{Zn}$ in salt-affected soils to assist balance the adverse effects of salts, and $\mathrm{Na}$ uptake surfaces of biochar [78]. The positives effects of biochar mainly are related to confine $\mathrm{Na}$ in the poor structure or indirectly by improving the physical and chemical properties of the soil, including 
increased activity microbes and water availability. Since biochar can $\mathrm{K}$ replace instead of $\mathrm{Na}$ in the plants, the application of biochar increase the amount of $\mathrm{K}$ and decrease the effects of $\mathrm{Na}$ in plants [9]. A study conducted by Feng [65], showed that the biochar amendment improved rice yield (Table 1) by decreasing tissue $\mathrm{Na}$ content $\mathrm{N} / \mathrm{K}$ ratio and increasing $\mathrm{K}$ content in the xylem under salinity conditions. Additionally, a significant increase in the $\mathrm{K}$ and $\mathrm{K} / \mathrm{Na}$ ratios was observed by Lashari [79], in leaf sap of maize grown under salt stress. Biochar can not only effect on salt-affected soils but can also improve the activity of rhizosphere microorganisms.

\subsection{Biochar improves rice growth in metal-contaminated soils}

Biochar has been considered as a solution for remediation of heavy metal contaminated soils. The principle behind the biochar-based remediation is to immobilize heavy metals, reduce their bioavailability in soils, and improve plant growth [80]. According to use of derived rice-straw biochar into the contaminated soil of $5 \%$ result, biochar had a reducing impact on elements such as $(\mathrm{Cd}, \mathrm{Cu}, \mathrm{Pb}$, and $\mathrm{Zn})$ diethylene triamine peracetic acid (DTPA) extractable of metal concentrations, in order $(\mathrm{Cd}<\mathrm{Cu}<\mathrm{Pb}<\mathrm{Zn}$, and 11, 17, 34 and $6 \%$ in compared to the control, respectively. It was showed that the immobilized metals were mainly bound in the soil organic matter fraction, chicken manure and green-waste biochars were used for immobilization of $\mathrm{Cd}, \mathrm{Cu}$, and $\mathrm{Pb}[70]$. Biochar derived from chicken manure increased shoot and root dry weights of Indian mustard (Brassica juncea) by 353 and $572 \%$, respectively. The dry weight increase was attributed to the reduced toxicity of metals and increased availability of nutrients, such as P and K [1]. Besides the application of conventional-biochars, should be produced a better capacity of biochar for metal fixation. However, after the making of Si-biochar derivative from bamboo biomass-milled with $\mathrm{K}_{2} \mathrm{SiO}_{3}$, the accumulation of As (III) in the edible part of spinach was reduced by 33.8 and $37.7 \%$ when grown in a soil amended with 2\% and 5\% Si-biochar, respectively [81]. Therefore, applying biochar in contaminated soils is found to alleviate the metal toxicity and add carbon inputs, improve the microbial activities and other factors like soil $\mathrm{pH}, \mathrm{CEC}$, and sorption of heavy metals [82].

\section{Conclusions}

Healthy soil is the main cornerstone and vital criteria for plant productivity. However, a large amount of agricultural land has been destroyed by the soil's problems such as acidity, alkalinity, salinity, nutrient deficiency, and various physical and anthropogenic limitations (heavy metals and organic pollutants). Biochars are known as a significant solution to the problem of soils. In this review, we can conclude that the biochar amendment is not only an effective but also an affordable way for the improving physical, chemical and biological properties of salt-affected soils, and rice productivity under salinity conditions. Since worldwide there is a massive production of agricultural waste, it could have the potential to provide a great deal of feedstock for biochar pyrolysis. The present challenges are not the solution of biochar for the soil improvement, it's rather recommended to select the proper feedstocks and preparation methods to achieve biochar for specific purposes and soil's need. Future studies should elevate for better addressing biochar functionalities. Therefore, new approaches for modifying functional groups include improving biochar effectiveness in adsorption or complexation of the chemicals in the soil, are strongly needed. This might be explored for maximizing biochar's potential as soil conditioners for more effectively improving soil properties and rice productivity in various salinity conditions.

\section{Declarations}

\subsection{Study Limitation}

This study did not provide a specific address about "Biochar Improve Rice Growth in Alkaline Soils". This is due to the limitation of accessibility to the applied research (fields experiment) resources.

\subsection{Acknowledgments}

The authors are grateful to Assoc. Dr. Abdurazak Alio Moussa for his assistance, advising this manuscript. 


\subsection{Competing Interests}

The authors declare that no conflict of interest exists in the publication of this work.

\section{How to Cite this Article:}

G. Anwari, A. Mandozai, and J. Feng, "Effects of Biochar Amendment on Soil Problems and Improving Rice Production under Salinity Conditions", Adv. J. Grad. Res., vol. 7, no. 1, pp. 45-63, Oct. 2019. doi:10.21467/ajgr.7.1.45-63

\section{References}

[1] Yu, Haowei, Weixin Zou, Jianjun Chen, Hao Chen, Zebin Yu, Jun Huang, Haoru Tang, Xiangying Wei, and Bin Gao. "Biochar Amendment Improves Crop Production in Problem Soils: A Review.” Journal of Environmental Management 232 (2019): 8-21.

[2] Zhang, Pei, and Yinguang Chen. "Polycyclic Aromatic Hydrocarbons Contamination in Surface Soil of China: A Review." Science of The Total Environment 605-606 (2017): 1011-1020.

[3] Fang, June, Lu Zhan, Yong Sik Ok, and Bin Gao. "Minireview of Potential Applications of Hydrochar Derived from Hydrothermal Carbonization of Biomass." Journal of Industrial and Engineering Chemistry 57 (2018): 15-21.

[4] Wu, Hailu, Xiaodong Che, Zhuhong Ding, Xin Hu, Anne Elise Creamer, Hao Chen, and Bin Gao. "Release of Soluble Elements from Biochars Derived from Various Biomass Feedstocks.” Environmental Science and Pollution Research 23, no. 2 (2015): 1905-15.

[5] Zhao, Yonggan, Shujuan Wang, Yan Li, Jia Liu, Yuqun Zhuo, Hongxiang Chen, Jing Wang, Lizhen Xu, and Zhentao Sun. "Extensive Reclamation of Saline-Sodic Soils with Flue Gas Desulfurization Gypsum on the Songnen Plain, Northeast China." Geoderma 321 (2018): 52-60.

[6] Chávez-García, Elizabeth, and Christina Siebe. "Rehabilitation of a Highly Saline-Sodic Soil Using a Rubble Barrier and Organic Amendments." Soil and Tillage Research 189 (2019): 176-88.

[7] Abdel-Fattah, Mohamed K. "Reclamation of Saline-Sodic Soils for Sustainable Agriculture in Egypt." The Handbook of Environmental Chemistry Sustainability of Agricultural Environment in Egypt: Part II, 2018, 69-92.

[8] Wang, Hongyu, Bin Gao, June Fang, Yong Sik Ok, Yingwen Xue, Kai Yang, and Xinde Cao. "Engineered Biochar Derived from Eggshell-Treated Biomass for Removal of Aqueous Lead." Ecologic Engineering 121 (2018): 124-29.

[9] Saifullah, Saad Dahlawi, Asif Naeem, Zed Rengel, and Ravi Naidu. "Biochar Application for the Remediation of Salt-Affected Soils: Challenges and Opportunities." Science of The Total Environment 625 (2018): 320-35.

[10] Mukherjee, Atanu, and Rattan Lal. "Biochar Impacts on Soil Physical Properties and Greenhouse Gas Emissions." Agronomy 3, no. 2 (2013): 313-39.

[11] Dugdug, A.A., Biochar for Saline-Sodic Soil Reclamation, Phosphorus Retention, and Crop Growth Improvement. 2018. https://era.library.ualberta.ca/items/6d83dad5-d268-4472-8a30-fd45cbd5c778

[12] Nguyen, B. T., Trinh, N. N., Le, C. M. T., Nguyen, T. T., Tran, T. V., Thai, B. V., \& Le, T. V., The interactive effects of biochar and cow manure on rice growth and selected properties of salt-affected soil. Archives of Agronomy and Soil Science, 64(12), 1744-1758, 2018.

[13] Arif, Muhammad, Talha Jan, Muhammad Riaz, Shah Fahad, Muhammad Saleem Arif, Muhammad Bilal Shakoor, Amanullah, and Fahd Rasul. "Advances in Rice Research for Abiotic Stress Tolerance." Advances in Rice Research for Abiotic Stress Tolerance, 2019, 585-614.

[14] Akram R, Fahad S, Masood N, Rasool A, Ijaz M, Ihsan MZ, Maqbool MM, Ahmad S, Hussain S, Ahmed M, Kaleem S. Plant Growth and Morphological Changes in Rice Under Abiotic Stress. InAdvances in Rice Research for Abiotic Stress Tolerance 2019 Jan 1 (pp. 69-85).

[15] Hipple, K., Washington soil atlas. Natural Resources Conservation Service, Washington , 2011. https://www.nrcs.usda.gov/Internet/FSE_DOCUMENTS/nrcs144p2_034094.pdf

[16] Wong VN, Greene RS, Dalal RC, Murphy BW. Soil carbon dynamics in saline and sodic soils: a review. Soil use and management. 2010 Mar;26(1):2-11.

[17] Omondi, Morris Oduor, Xin Xia, Alphonse Nahayo, Xiaoyu Liu, Punhoon Khan Korai, and Genxing Pan. "Quantification of Biochar Effects on Soil Hydrological Properties Using Meta-Analysis of Literature Data." Geoderma 274 (2016): 28-34.

[18] Karagöz, Pinar, Indre V. Rocha, Melek Özkan, and Irini Angelidaki. "Alkaline Peroxide Pretreatment of Rapeseed Straw for Enhancing Bioethanol Production by Same Vessel Saccharification and Co-Fermentation." Bioresource Technology 104 (2012): 34957.

[19] Zheng, Shao Jian. "Crop Production on Acidic Soils: Overcoming Aluminium Toxicity and Phosphorus Deficiency." Annals of Botany 106, no. 1 (January 2010): 183-84.

[20] Hsieh, En-Jung, and Brian M. Waters. "Alkaline Stress and Iron Deficiency Regulate Iron Uptake and Riboflavin Synthesis Gene Expression Differently in Root and Leaf Tissue: Implications for Iron Deficiency Chlorosis." Journal of Experimental Botany 67, no. 19 (July 2016): 5671-85.

[21] Waters, Brian M., Keenan Amundsen, and George Graef. "Gene Expression Profiling of Iron Deficiency Chlorosis Sensitive and Tolerant Soybean Indicates Key Roles for Phenylpropanoids under Alkalinity Stress.” Frontiers in Plant Science 9 (2018).

[22] R. Cernansky, "Agriculture: State-of-the-art soil", Nature, 2019. [Online]. Available: https://www.nature.com/articles/517258a.

[23] Letey and P. Vaughan, "Soil type, crop and irrigation technique affect nitrogen leaching to groundwater", California Agriculture, vol. 67, no. 4, pp. 231-241, 2013.

[24] Läuchli, A., and S. R. Grattan. "Plant Stress under Non-Optimal Soil PH." Plant Stress Physiology, n.d., 201-16.

[25] Good, Allen. “Toward Nitrogen-Fixing Plants." Science 359, no. 6378 (2018): 869-70. 
Anwari et al., Adv. J. Grad. Res.; Vol. 7, Issue 1, pp: 45-63, January 2020

[26] Finkel, Richard S., Eugenio Mercuri, Basil T. Darras, Anne M. Connolly, Nancy L. Kuntz, Janbernd Kirschner, Claudia A. Chiriboga, et al. "Nusinersen versus Sham Control in Infantile-Onset Spinal Muscular Atrophy." New England Journal of Medicine 377, no. 18 (February 2017): 1723-32.

[27] Li, Shili, Yongqin Liu, Jiao Wang, Liang Yang, Shuting Zhang, Chen Xu, and Wei Ding. "Soil Acidification Aggravates the Occurrence of Bacterial Wilt in South China." Frontiers in Microbiology 8 (2017).

[28] Lü, Huixiong, Ce-Hui Mo, Hai-Ming Zhao, Lei Xiang, Athanasios Katsoyiannis, Yan-Wen Li, Quan-Ying Cai, and Ming-Hung Wong. "Soil contamination and sources of phthalates and its health risk in China: a review." Environmental research 164 (2018): 417429.

[29] Keyte, Ian J., Roy M. Harrison, and Gerhard Lammel. "Chemical Reactivity and Long-Range Transport Potential of Polycyclic Aromatic Hydrocarbons - a Review.” Chemical Society Reviews 42, no. 24 (2013): 9333.

[30] Lv, C., J. Chen, and X. Wang. "Evaluation of Surfactant Performance in in Situ Foam Flushing for Remediation of Dichlorodiphenyltrichloroethane-Contaminated Soil.” International Journal of Environmental Science and Technology 14, no. 3 (2017): 631-38.

[31] Mubarak, N. M., Y. T. Fo, Hikmat Said Al-Salim, J. N. Sahu, E. C. Abdullah, S. Nizamuddin, N. S. Jayakumar, and P. Ganesan. "Removal of Methylene Blue and Orange-G from Waste Water Using Magnetic Biochar." International Journal of Nanoscience 14, no. 04 (2015): 1550009

[32] Finnegan and W. Chen, "Arsenic Toxicity: The Effects on Plant Metabolism", Frontiers in Physiology, vol. 3, 2012.

[33] Inyang, Mandu I., Bin Gao, Ying Yao, Yingwen Xue, Andrew Zimmerman, Ahmed Mosa, Pratap Pullammanappallil, Yong Sik Ok, and Xinde Cao. "A Review of Biochar as a Low-Cost Adsorbent for Aqueous Heavy Metal Removal." Critical Reviews in Environmental Science and Technology 46, no. 4 (December 2015): 406-33.

[34] Lian, F. and B. Xing, Black carbon (biochar) in water/soil environments: molecular structure, sorption, stability, and potential risk. Environmental science \& technology, 2017. 51(23): p. 13517-13532.

[35] Wei, Binggan, and Linsheng Yang. "A Review of Heavy Metal Contaminations in Urban Soils, Urban Road Dusts and Agricultural Soils from China." Microchemical Journal 94, no. 2 (2010): 99-107.

[36] Weber, Kathrin, and Peter Quicker. "Properties of Biochar." Fuel 217 (2018): 240-61.

[37] Xiao, Xin, Baoliang Chen, Zaiming Chen, Lizhong Zhu, and Jerald L. Schnoor. "Insight into multiple and multilevel structures of biochars and their potential environmental applications: a critical review." Environmental science \& technology 52, no. 9 (2018): 5027-5047.

[38] Dai, Zhongmin, Xiaojie Zhang, C. Tang, Niaz Muhammad, Jianjun Wu, Philip C. Brookes, and Jianming Xu. "Potential Role of Biochars in Decreasing Soil Acidification - A Critical Review." Science of The Total Environment 581-582 (2017): 601-11.

[39] Blanco-Canqui, Humberto. "Biochar and Soil Physical Properties." Soil Science Society of America Journal 81, no. 4 (2017): 687.

[40] Somerville, Michael, and Sharif Jahanshahi. "The Effect of Temperature and Compression during Pyrolysis on the Density of Charcoal Made from Australian Eucalypt Wood.” Renewable Energy 80 (2015): 471-78.

[41] Pimchuai, Anuphon, Animesh Dutta, and Prabir Basu. "Torrefaction of Agriculture Residue To Enhance Combustible Properties†." Energy \& Fuels 24, no. 9 (2010): 4638-45.

[42] Ahmad, Mahtab, Anushka Upamali Rajapaksha, Jung Eun Lim, Ming Zhang, Nanthi Bolan, Dinesh Mohan, Meththika Vithanage, Sang Soo Lee, and Yong Sik Ok. "Biochar as a sorbent for contaminant management in soil and water: a review." Chemosphere 99 (2014): 19-33.

[43] Xu, Y. and B. Chen, Organic carbon and inorganic silicon speciation in rice-bran-derived biochars affect its capacity to adsorb cadmium in solution. Journal of soils and sediments, 2015. 15(1): p. 60-70.

[44] Naeem, Muhammad Asif, Muhammad Imran, Muhammad Tahir, Muhammad Amjad, Behzad Murtaza, Ghulam Abbas, Sajjad Ahmad, and Naveed Ahmad. "Temporal Variations In Soil Chemical Properties And Nutrient Availability In Response To Maize Biochar Produced At Different Temperatures." Pakistan Journal of Agricultural Sciences 56, no. 2 (2019): 291-300.

[45] Rajapaksha, A.U., et al., Engineered/designer biochar for contaminant removal/immobilization from soil and water: potential and implication of biochar modification. Chemosphere, 2016. 148: p. 276-291.

[46] Muñoz, Edmundo, Gustavo Curaqueo, Mara Cea, Leonardo Vera, and Rodrigo Navia. "Environmental Hotspots in the Life Cycle of a Biochar-Soil System." Journal of Cleaner Production 158 (2017): 1-7.

[47] Liu, Liang, Guoqing Shen, Mingxing Sun, Xinde Cao, Guofeng Shang, and Ping Chen. "Effect of Biochar on Nitrous Oxide Emission and Its Potential Mechanisms." Journal of the Air \& Waste Management Association 64, no. 8 (2014): 894-902

[48] Fidel, Rivka B., David A. Laird, Michael L. Thompson, and Michael Lawrinenko. "Characterization and Quantification of Biochar Alkalinity." Chemosphere 167 (2017): 367-73.

[49] Shi, Ren-Yong, Zhi-Neng Hong, Jiu-Yu Li, Jun Jiang, M. Abdulaha-Al Baquy, Ren-Kou Xu, and Wei Qian. "Mechanisms for Increasing the PH Buffering Capacity of an Acidic Ultisol by Crop Residue-Derived Biochars." Journal of Agricultural and Food Chemistry 65, no. 37 (August 2017): 8111-19.

[50] Ippolito, J.a., T.f. Ducey, K.b. Cantrell, J.m. Novak, and R.d. Lentz. "Designer, Acidic Biochar Influences Calcareous Soil Characteristics." Chemosphere 142 (2016): 184-91.

[51] Fahad, Shah, Abdul Rehman, Babar Shahzad, Mohsin Tanveer, Shah Saud, Muhammad Kamran, Muhammad Ihtisham, Shahid Ullah Khan, Veysel Turan, and Muhammad Habib ur Rahman. "Rice Responses and Tolerance to Metal/Metalloid Toxicity." In Advances in Rice Research for Abiotic Stress Tolerance, pp. 299-312. Woodhead Publishing, 2019.

[52] Ahmad, Zahoor, Bin Gao, Ahmed Mosa, Haowei Yu, Xianqiang Yin, Asaad Bashir, Hossein Ghoveisi, and Shengsen Wang. "Removal of $\mathrm{Cu}(\mathrm{II}), \mathrm{Cd}(\mathrm{II})$ and $\mathrm{Pb}$ (II) Ions from Aqueous Solutions by Biochars Derived from Potassium-Rich Biomass." Journal of Cleaner Production 180 (2018): 437-49.

[53] Qian, Linbo, Xiao Shang, Bo Zhang, Wenying Zhang, Anqi Su, Yun Chen, Da Ouyang, Lu Han, Jingchun Yan, and Mengfang Chen. "Enhanced Removal of Cr(VI) by Silicon Rich Biochar-Supported Nanoscale Zero-Valent Iron." Chemosphere 215 (2019): 739-45. 
[54] Ding, Zhuhong, Xin Hu, Yongshan Wan, Shengsen Wang, and Bin Gao. "Removal of Lead, Copper, Cadmium, Zinc, and Nickel from Aqueous Solutions by Alkali-Modified Biochar: Batch and Column Tests." Journal of Industrial and Engineering Chemistry 33 (2016): 239-45.

[55] Riaz, Muhammad, Muhammad Saleem Arif, Qaiser Hussain, Shahbaz Ali Khan, Hafiz Muhammad Tauqeer, Tahira Yasmeen, Muhammad Arslan Ashraf, et al. "Application of Biochar for the Mitigation of Abiotic Stress-Induced Damages in Plants." Plant Tolerance to Environmental Stress, October 2019, 285-304.

[56] Khan, Sardar, Ning Wang, Brian J. Reid, Alessia Freddo, and Chao Cai. "Reduced Bioaccumulation of PAHs by Lactuca Satuva L. Grown in Contaminated Soil Amended with Sewage Sludge and Sewage Sludge Derived Biochar." Environmental Pollution 175 (2013): 64-68.

[57] Trinh, Bao-Son, David Werner, and Brian J Reid. "Application of a Full-Scale Wood Gasification Biochar as a Soil Improver to Reduce Organic Pollutant Leaching Risks.” Journal of Chemical Technology \& Biotechnology 92, no. 8 (2017): 1928-37.

[58] Lyu, Honghong, Bin Gao, Feng He, Andrew R. Zimmerman, Cheng Ding, Jingchun Tang, and John C. Crittenden. "Experimental and Modeling Investigations of Ball-Milled Biochar for the Removal of Aqueous Methylene Blue." Chemical Engineering Journal 335 (2018): 110-19.

[59] Mia, Shamim, Feike A. Dijkstra, and Balwant Singh. "Enhanced Biological Nitrogen Fixation and Competitive Advantage of Legumes in Mixed Pastures Diminish with Biochar Aging.” Plant and Soil 424, no. 1-2 (2018): 639-51.

[60] Jinyang,Wang, Xiaojian Pan, Yinglie Liu, Xiaolin Zhang, and Zhengqin Xiong. "Effects of Biochar Amendment in Two Soils on Greenhouse Gas Emissions and Crop Production." Plant and Soil 360, no. 1-2 (2012): 287-98.

[61] Asai, Hidetoshi, Benjamin K. Samson, Haefele M. Stephan, Khamdok Songyikhangsuthor, Koki Homma, Yoshiyuki Kiyono, Yoshio Inoue, Tatsuhiko Shiraiwa, and Takeshi Horie. "Biochar Amendment Techniques for Upland Rice Production in Northern Laos." Field Crops Research 111, no. 1-2 (2009): 81-84.

[62] Dong, Da, Qibo Feng, Kim Mcgrouther, Min Yang, Hailong Wang, and Weixiang Wu. "Effects of Biochar Amendment on Rice Growth and Nitrogen Retention in a Waterlogged Paddy Field." Journal of Soils and Sediments 15, no. 1 (2014): 153-62.

[63] Bian, Rongjun, Stephen Joseph, Liqiang Cui, Genxing Pan, Lianqing Li, Xiaoyu Liu, Afeng Zhang, et al. "A Three-Year Experiment Confirms Continuous Immobilization of Cadmium and Lead in Contaminated Paddy Field with Biochar Amendment." Journal of Hazardous Materials 272 (2014): 121-28.

[64] Kamara, Alie, Hawanatu Sorie Kamara, and Mohamed Saimah Kamara. "Effect of Rice Straw Biochar on Soil Quality and the Early Growth and Biomass Yield of Two Rice Varieties.” Agricultural Sciences 06, no. 08 (2015): 798-806.

[65] Jin, Feng, Cheng Ran, Qul Aqa Anwari, Yan Qiu Geng, Li Ying Guo, Jian Bo Li, Dong Han, Xian Qin Zhang, Xu Liu, and Xi Wen Shao. "Effects of Biochar on Sodium Ion Accumulation, Yield and Quality of Rice in Saline-Sodic Soil of the West of Songnen Plain, Northeast China." Plant, Soil and Environment 64, no. No. 12 (2018): 612-18.

[66] Ran, Cheng, Anwari Gulaqa, Jing Zhu, Xiaowei Wang, Siqi Zhang, Yanqiu Geng, Liying Guo, Feng Jin, and Xiwen Shao. "Benefits of Biochar for Improving Ion Contents, Cell Membrane Permeability, Leaf Water Status and Yield of Rice Under Saline-Sodic Paddy Field Condition.” Journal of Plant Growth Regulation, December 2019.

[67] Xiang, Yangzhou, Qi Deng, Honglang Duan, and Ying Guo. "Effects of Biochar Application on Root Traits: Meta-Analysis." GCB Bioenergy 9, no. 10 (2017): 1563-72.

[68] Zwieten, Lukas Van, Claudia Kammann, Maria Luz Cayuela, Bhupinder Pal Singh, Stephen Joseph, Stephen Kimber, Scott Donne, Tim Clough, and Kurt A. Spokas. Biochar effects on nitrous oxide and methane emissions from soil. No. COLECCION GENERAL/631.422 B615bi2. En: Biochar for environmental management: science, technology and implementation. London, GB: Routledge, 2015. http://www.warrencc.org.au/wp-content/uploads/2015/12/Biochar-effects-on-nitrous-oxide-methane-emissionsfrom-soil.

[69] Kim, Hyuck-Soo, Kwon-Rae Kim, Jae E. Yang, Yong Sik Ok, Gary Owens, Thomas Nehls, Gerd Wessolek, and Kye-Hoon Kim. "Effect of Biochar on Reclaimed Tidal Land Soil Properties and Maize (Zea Mays L.) Response." Chemosphere 142 (2016): 153-59.

[70] Lu, Kouping, Xing Yang, Gerty Gielen, Nanthi Bolan, Yong Sik Ok, Nabeel Khan Niazi, Song Xu, et al. "Effect of Bamboo and Rice Straw Biochars on the Mobility and Redistribution of Heavy Metals $(\mathrm{Cd}, \mathrm{Cu}, \mathrm{Pb}$ and $\mathrm{Zn}$ ) in Contaminated Soil." Journal of Environmental Management 186 (2017): 285-92.

[71] Magistad, O. C. "Plant Growth Relations on Saline and Alkali Soils." The Botanical Review 11, no. 4 (1945): 181-230.

[72] Merry, Richard H., Leonie R. Spouncer, Rob W. Fitzpatrick, Phil J. Davies, David A. Bruce, T. McVicar, L. Rui, and J. Walker. "Regional prediction of soil profile acidity and alkalinity." ACIAR MONOGRAPH SERIES 84 (2002): 155-164.

[73] Amin, Abu El-Eyuoon Abu Zied, and Mamdouh A Eissa. "Biochar Effects on Nitrogen and Phosphorus Use Efficiencies of Zucchini Plants Grown in a Calcareous Sandy Soil.” Journal of Soil Science and Plant Nutrition 17, no. 4 (2017): 912-21.

[74] Shanthi, P.V., et al., Characterization Of Selected Biochars To Determine Their Suitability As A Soil Amendment From A Climate Change Mitigation Perspective. Octa Journal of Environmental Research, 2017. 5(1).

[75] Trinidad, Jennylyn L., Herra L. Grajo, Jose B. Abucay, and Ajay Kohli. "Cereal Root Proteomics for Complementing the Mechanistic Understanding of Plant Abiotic Stress Tolerance.” Agricultural Proteomics Volume 2, 2016, 19-51.

[76] Gunes, A., A. Inal, O. Sahin, M. B. Taskin, O. Atakol, and N. Yilmaz. "Variations in Mineral Element Concentrations of Poultry Manure Biochar Obtained at Different Pyrolysis Temperatures, and Their Effects on Crop Growth and Mineral Nutrition." Soil Use and Management 31, no. 4 (January 2015): 429-37.

[77] Kartika, Kartika, Benyamin Lakitan, Andi Wijaya, Sabaruddin Kadir, Laily Ilman Widur, Erna Siaga, and Mei Meihana. "Effects of particle size and application rate of rice-husk biochar on chemical properties of tropical wetland soil, rice growth and yield." Australian J. of Crop Sci. 12, no. 05 (2018): 817-826.

[78] Rostamian, R., M. Heidarpour, M. Afyuni, and S. F. Mousavi. "Characterization and Sodium Sorption Capacity of Biochar and Activated Carbon Prepared from Rice Hus." (2018).

[79] Lashari, Muhammad Siddique, Yingxin Ye, Haishi Ji, Lianqing Li, Grace Wanjiru Kibue, Haifei Lu, Jufeng Zheng, and Genxing Pan. "Biochar-Manure Compost in Conjunction with Pyroligneous Solution Alleviated Salt Stress and Improved Leaf Bioactivity of Maize 
Anwari et al., Adv. J. Grad. Res.; Vol. 7, Issue 1, pp: 45-63, January 2020

in a Saline Soil from Central China: a 2-Year Field Experiment.” Journal of the Science of Food and Agriculture 95, no. 6 (2014): $1321-27$.

[80] Mosa, A., M.F. El-Banna, and B. Gao, Biochar filters reduced the toxic effects of nickel on tomato (Lycopersicon esculentum L.) grown in nutrient film technique hydroponic system. Chemosphere, 2016. 149: p. 254-262.

[81] Zama, Eric F., Brian J. Reid, Guo-Xin Sun, Hai-Yan Yuan, Xiao-Ming Li, and Yong-Guan Zhu. "Silicon (Si) Biochar for the Mitigation of Arsenic (As) Bioaccumulation in Spinach ( Spinacia Oleracean ) and Improvement in the Plant Growth." Journal of Cleaner Production 189 (2018): 386-95.

[82] Lwin, Chaw Su, Byoung-Hwan Seo, Hyun-Uk Kim, Gary Owens, and Kwon-Rae Kim. "Application of Soil Amendments to Contaminated Soils for Heavy Metal Immobilization and Improved Soil Quality - a Critical Review.” Soil Science and Plant Nutrition 64, no. 2 (2018): 156-67.

\section{Publish your books with AIJR publisher- \\ $\checkmark$ Publish with ISBN and DOI. \\ $\checkmark \quad$ Publish Thesis/Dissertation as Monograph. \\ $\checkmark \quad$ Publish Book Monograph. \\ $\checkmark$ Publish Edited Volume/ Book. \\ $\checkmark$ Publish Conference Proceedings \\ $\checkmark \quad$ Retain full copyright of your books. \\ Submit your manuscript at books.aijr.org}

Publish your research article in AIJR journals-

$\checkmark \quad$ Online Submission and Tracking

$\checkmark$ Peer-Reviewed

$\checkmark$ Rapid decision

$\checkmark \quad$ Immediate Publication after acceptance

$\checkmark \quad$ Articles freely available online

$\checkmark \quad$ Retain full copyright of your article. Submit your article at journals.aijr.in 